\title{
Is lead toxicity still a risk to U.S. children?
}

by Karrie Heneman and Sheri Zidenberg-Cherr

Elevated blood-lead levels put children at risk for neurobehavioralcognitive deficits, such as IQ deficiency, behavioral disorders and impaired hearing. We examined several factors that contribute to elevated lead levels in U.S. children to help define the extent to which lead toxicity from these sources continues to be a problem. The results of our review suggest that elevated levels of lead in paint, dust, soil, imported pottery and ceramic ware, ethnic remedies, and some imported candies continue to be areas of concern, while typical levels in food products appear to be acceptable. It is important to continue monitoring lead levels in children as well as in environmental and food sources.

\footnotetext{
$\mathrm{T}^{\mathrm{h}}$
}

he U.S. Environmental Protection Agency (EPA) estimates that 430,000 American children between 1 and 5 years old have blood-lead levels at or above 10 micrograms per deciliter $(\mu \mathrm{g} / \mathrm{dl})$ (EPA 2004b), costing the United States an estimated $\$ 43.4$ billion dollars annually (Landrigan et al. 2002). Elevated blood-lead levels put children at risk for deficits in neurobehavioralcognitive performance that manifest later in childhood (Needleman et al. 1990). These deficits include IQ deficiency, behavioral disorders and impaired hearing. In addition, 400,000 more children may be yet undiagnosed (GAO 1999).

Furthermore, these deficits may persist even 20 years after exposure (Bernard and McGeehin 2003), since lead is sequestered in bone. While the body can remove it, some amount remains behind and with chronic exposure can accumulate. There may be no safe level of lead. For example, IQ has been shown to be adversely affected at levels below $10 \mu \mathrm{g} / \mathrm{dl}$, by as much as 7.4

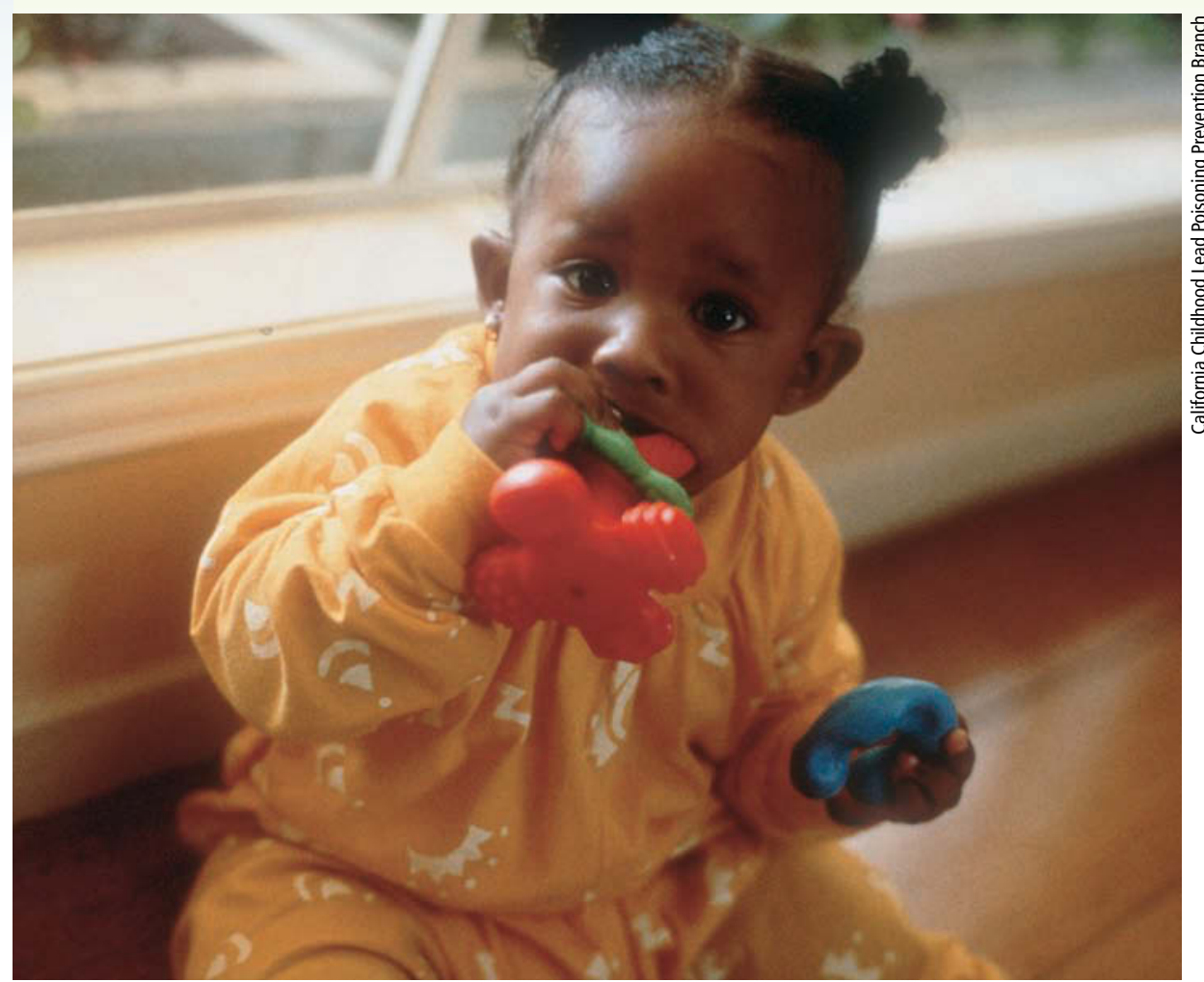

Chewing and sucking on things is normal in young children, but it can increase the risk of lead poisoning if lead is present. Lead was removed from paint in 1978, but dust from older paint can easily be ingested by children via their hands or toys.

points (Canfield et al. 2003), suggesting that any exposure to lead can put a child at risk. What is most disconcerting is the fact that sustained, low-level lead exposure can go unchecked because such neurological abnormalities may have no apparent symptoms (Koplan 2002).

Young children are at the greatest risk of lead toxicity, as their body burden (the total amount of lead in the body at a given time) is influenced by weight. Children between 1 and 4 years old face additional risks because of pica (ingestion of nonfood substances) and hand-to-mouth activity (Mielke and Reagan 1998). These factors are of particular concern because lead can damage a child's rapidly developing nervous system, making the threat of permanent neurological damage greatest during the first 6 years of life (CDC 1991).Research has shown that the negative effects of lead on the cognitive function of children are persistent across cultures, racial and ethnic groups, and social and economic classes (Nordin et al. 1994).
Other known risk factors for lead toxicity among children include: (1) living in housing built before 1978, when the federal government banned the use of lead-based paint for houses; (2) recent or ongoing renovation in pre1978 housing; (3) peeling paint in pre1978 housing; (4) urban residence; (5) low-socioeconomic status; (6) the use of imported pottery and ceramic ware; and (7) the use of traditional ethnic medicines (CDC 1991).

In the past, lead in the ambient air and in food contributed much more to overall exposure of the general U.S. population than it does now. Because lead from these sources has been drastically reduced, blood-lead levels in U.S. children and the general population are lower than they were 1 or 2 decades ago (EPA 2004b). However, despite the decreased use of lead in food canning, gasoline and paint, lead will remain in our environment for many years. While it is critical that recognized sources of lead be minimized in a child's environment, 
eradicating all sources of excessive lead exposure would be difficult and expensive, making continual surveillance for lead toxicity imperative.

In an effort to detect and treat cases of lead toxicity, government agencies such as the U.S. Centers for Disease Control and Prevention (CDC), and organizations such as the American Academy of Pediatrics, have recommended universal screening for all children aged 6 months to 6 years participating in low-income programs. This concept has been met with mixed responses from the medical community. Proponents suggest that the plan meets all the cost-benefit criteria for suggested population-based screening and that it would be cost effective if the prevalence of lead poisoning in the population was even as low as $0.1 \%$. Opponents argue that the prevalence of elevated bloodlead levels is low, and that there is no effective therapy for children with low lead levels. Indeed, except in cases of extreme, acute exposure, therapy for children with elevated blood-lead levels consists of education and efforts to remove sources of lead from the child's environment (DHS 2003a).

Current surveillance systems may not provide accurate estimates of lead toxicity among children. Despite national recommendations to screen all children participating in low-income programs, screening rates vary and remain low; an estimated 400,000 U.S. children with elevated blood-lead levels are undiagnosed (GAO 1999). While the national childhood blood-lead surveillance program collects state data, reporting is not consistent. In California, for example, only cases where blood-lead levels exceeded $25 \mu \mathrm{g} / \mathrm{dl}$ were reported prior to Jan. 1, 2003.

Nationally representative surveys and local prevalence data is also collected, but these report blood-lead levels at or above $10 \mu \mathrm{g} / \mathrm{dl}$. Recent estimates from the National Health and Nutrition Examination Survey (NHANES) IV showed that the prevalence of blood-lead levels greater than or equal to $10 \mu \mathrm{g} / \mathrm{dl}$ among American children 1 to 5 years old is 2.2\% (Meyer et al. 2003). Similarily, CDC 2003 surveillance data indicates $2.04 \%$ prevalence of elevated blood-lead levels in children under 6 (CDC 2003).
Although this information is useful, the prevalence of low-level lead toxicity (less than or equal to $10 \mu \mathrm{g} / \mathrm{dl}$ ) across populations has not been documented. Our research group collected lead toxicity data in 1996 from children in four California counties, representing both low- and high-risk environments (where high risk was defined as being of lowincome and living in houses built before 1950). We found that approximately $13 \%$ of the children had blood-lead levels greater than $5 \mu \mathrm{g} / \mathrm{dl}$. This is of concern given that other researchers have found detrimental effects on IQ (Canfield et al. 2003) and reading and math scores at blood-lead levels from 5 to $10 \mu \mathrm{g} / \mathrm{dl}$ (Lanphear et al. 2000).

We review several factors that contribute to elevated lead levels in children living in the United States, to help define the extent to which lead toxicity from environmental and food sources continues to be a problem. It is anticipated that these results will help revise gasoline prior to its ban in the United States in 1996.

In 1999, the EPA estimated that $8 \%$ of American children were served by lead-contaminated water systems, possibly contributing up to $20 \%$ of a child's lead exposure. The Safe Drinking Water Act of 1974, created to improve U.S. drinking water by establishing tolerable levels of a variety of contaminants (including chemicals), recommended that no amount of lead in tap water is safe. However, this was solely a recommendation and was not enforced (EPA 2005).

Contamination of water by lead generally occurs during the last phases of water delivery, making it difficult to regulate. Upon entering the plumbing system of a house or building, the corrosiveness of water causes lead to leach from the pipes (plumbing may have lead pipes, solder or other materials) (EPA 2005). The Lead and Copper Rule, published by EPA in 1991, aimed to reduce the corrosivity of water through

\section{Sustained, low-level lead exposure may result in neurological abnormalities without any apparent symptoms.}

existing education programs so that the Healthy People 2010 objective (a set of national health goals) to eliminate all elevated blood-lead levels in children can be met (DHHS 2000).

\section{Lead in the environment}

The U.S. Department of Health and Human Services has referred to lead poisoning as the most common environmental pediatric problem for young children (CDC 1991). Major environmental sources of lead poisoning in children are lead-contaminated water, lead-based paint, and soil and dust. Lead exists in the environment as a result of geological activity and human actions, and occurs naturally in soil and dust (natural lead). Through a global assessment of atmospheric trace metals, Nriagu and Pacyna (1988) concluded that lead as an environmental pollutant is essentially caused by human action. Human activities include the mining and smelting of ores, the combustion of fossil fuels and the dissemination of lead through industrial processes; the most pervasive is tetra ethyl lead, which was used as an antiknock additive in treatment. EPA reviews of water systems in 2004 found that the Lead and Copper Rule was $96 \%$ effective for systems serving 3,300 people or more (Millett 2005). In response to these findings, EPA recently issued the Drinking Water Lead Reduction Plan to help further reduce lead levels (Millett 2005), and preliminary monitoring results released by EPA in March 2005 reported that national lead levels in water were no longer elevated (Davis 2005).

Single paint chips may contain between 6.45 and 32.25 milligrams lead per square inch (1 and 5 milligrams per square centimeter) (CDC 1991), and analysis of NHANES III data shows that children living in housing built prior to 1946 are 5.1 times as likely to have elevated blood-lead levels (Bernard and McGeehin 2003). Estimates from 1998 show that $40 \%$ of homes in the United States still contain lead-based paint, 16\% of homes have hazardous levels of lead in dust, and $7 \%$ of homes have hazardous soil lead levels (EPA 2004b). EPA estimates that between 5.9 million and 11.7 million children are exposed to lead in dust and soil annually (EPA 2004a). 


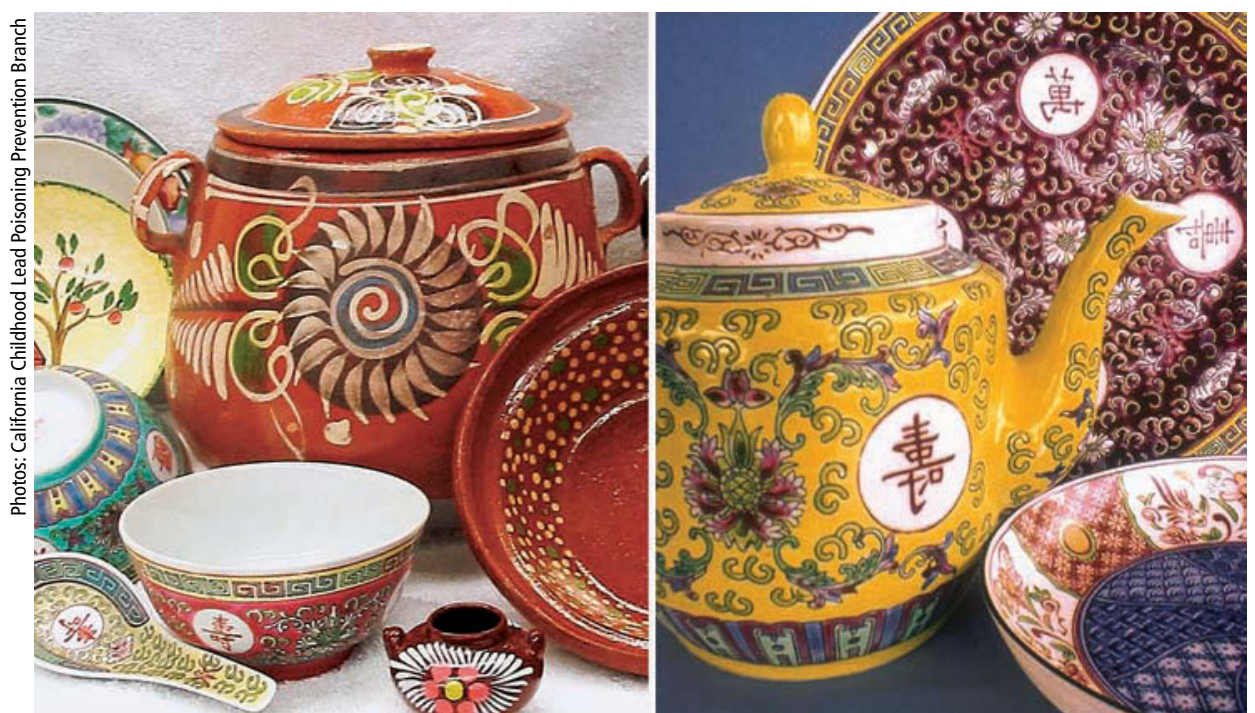

Imported ceramic cookware may contain high levels of lead in the decoration. Lead leaches into food during cooking and storage, especially with acidic foods.

Soil becomes contaminated with lead through three methods: the weathering and chipping of lead-based paint, industrial pollution or deposition from the use of leaded gasoline. EPA regulations have greatly reduced the risk of lead exposure from industrial pollution or the use of leaded gasoline, but exposure to leadbased paint continues to be a problem.

\section{Other sources of lead}

\section{Imported ceramic cookware.}

Another potential source of lead contamination is imported ceramic cookware. One case study reported that a child who regularly consumed fruit punch stored in a lead-glazed urn had an increase in blood-lead levels from $22.79 \mu \mathrm{g} / \mathrm{dl}$ to $95.32 \mu \mathrm{g} / \mathrm{dl}$ dur-

\begin{tabular}{|c|c|c|}
\hline Food group & $\begin{array}{c}\text { Mean lead } \\
\text { concentration }\end{array}$ & $\begin{array}{l}\text { Standard } \\
\text { deviation }\end{array}$ \\
\hline & \multicolumn{2}{|c|}{$\ldots \ldots \mu \mu g / g$} \\
\hline Dairy & 0.002 & 0.005 \\
\hline Meat, fish, poultry & 0.003 & 0.006 \\
\hline $\begin{array}{l}\text { Grain, cereal } \\
\text { products }\end{array}$ & 0.003 & 0.006 \\
\hline Vegetables & 0.004 & 0.006 \\
\hline Fruit, fruit juices & 0.004 & 0.006 \\
\hline $\begin{array}{l}\text { Oils, fats, } \\
\text { shortening }\end{array}$ & 0.003 & 0.007 \\
\hline Sugar, desserts & 0.002 & 0.007 \\
\hline Beverages & 0.007 & 0.007 \\
\hline Mixed dishes & 0.002 & 0.003 \\
\hline Infant food & 0.003 & 0.005 \\
\hline
\end{tabular}

ing a 4-week period. Consumption of fruit punch from the same container by others resulted in a $20 \%$ increase in blood-lead concentrations (Matte et al. 1994). Glazes used on traditional pots imported from both South American and Asian countries may contain lead. Lead can leach into food when these contaminated pots are used for cooking or storage. Cooking with acidic foods (such as tomatoes, vinegar, alcohol or soy sauce) in these pots is of special concern because their low $\mathrm{pH}$ enhances the leaching process (DHS 2003b).

Ethnic remedies. The use of folk medicine by ethnic groups has also been associated with lead toxicity (CDC 1993). A recent analysis of 70 ayurvedic products (those based on traditional medicine in India) from stores in the Boston area showed that almost $20 \%$ contained lead, ranging from 5 $\mu \mathrm{g} / \mathrm{g}$ to $37,000 \mu \mathrm{g} / \mathrm{g}$ per sample (Saper et al. 2004). Surma, also know as kohl, kajal or al-kahl, is an ethnic remedy that is applied to the eyes of children in primarily consists of lead sulphide, and use may result in elevated blood-lead levels, possibly increasing blood lead in children by as much as $8.5 \mu \mathrm{g} / \mathrm{dl}$ (Sprinkle 1995).

In Latino communities, the use of azarcon and greta, two herbal remedies used to treat intestinal and stomach ailments, may result in elevated blood-lead levels. Samples of azarcon, an orange powder, contained large some Asian communities. This powder amounts of lead tetroxide, while greta, a bright yellow or orange powder, also contained high lead levels. Other folk medicines associated with lead poisoning include ghasard, an Indian remedy; litargirio, a Hispanic folk remedy; and paylooah, a medicine used in the Hmong culture (Sprinkle 1995; CDC 1993). In light of these findings, culturally sensitive warnings about these products are warranted.

\section{Lead in food}

Data from 1990 suggests that children up to 16 years old consume between $3.8 \mu \mathrm{g}$ and $8.5 \mu \mathrm{g}$ of lead per day from food, water and beverages, meaning that approximately $16 \%$ of a 2 -yearold child's daily intake of lead may come from food (Abadin and Llados 1999) (table 1).

Candy. Recent warnings issued by the U.S. Food and Drug Administration (FDA) and state health departments have raised concern about lead contamination in candy imported from Mexico (FDA 2004a; DHS 2005). The $\mathrm{CDC}$ reported that, based on routine blood-lead screenings, six California children suffered from lead toxicity after eating tamarind- and chili-flavored candy imported from Mexico. The FDA then found between $0.3 \mu \mathrm{g}$ to $0.4 \mu \mathrm{g}$ of lead per gram of candy. The California Department of Health Services independently found elevated lead levels in candy as well $(>0.5 \mu \mathrm{g}$ of lead per gram) (DHS 2005). It is believed that lead contamination may be introduced from ingredients or occur during candy processing such as drying, storing and grinding (CDC 2005), or that lead may leach into the candy from tainted wrappers (Fuortes and Bauer 2000).

Currently, there is no regulatory limit for lead in food, but the FDA has established a Provisional Daily Total Tolerable Intake of $6 \mu \mathrm{g}$ of lead per 30-gram food serving $(0.2 \mu \mathrm{g} / \mathrm{g})$ (Lynch et al. 2000). The candies described above each weighed 30 grams or more per piece, so consumption of a single candy could deliver lead in an amount greater than the Provisional Daily Total Tolerable Intake (August and Brooks 2004); however, factors such as nutritional status, age and gender influence the amount of lead absorbed after consumption. 
As a result, it is difficult to accurately determine the true risk posed by consumption of these products.

Chocolate. The issue of chocolate as a source of lead exposure among children has also recently surfaced in the media, although warnings issued by state departments of health only pertain to imported candy. Contamination of chocolate by lead is thought to occur because the majority of beans are grown in locations that still use leaded gasoline. Despite high per-capita consumption of chocolate in the United States, there is a paucity of data on lead concentrations in chocolate products.

The American Environmental Safety Institute, an environmental advocacy group based in California, tested a variety of chocolate products and reported that they contained between $0.00157 \mu \mathrm{g}$ and $0.105 \mu \mathrm{g}$ lead per gram chocolate. The USDA Total Diet Study (FDA 2004b) found between 0.0 and $0.110 \mu \mathrm{g}$ lead per gram chocolate. Analysis of chocolate samples by our research group yielded similar results. Mean lead levels ranged from 0.0010 to $0.0965 \mu \mathrm{g}$ lead per gram chocolate (table 2).

The Codex Alimentarius, global food standards developed by the Food and Agriculture Organization (FAO) and World Health Organization (WHO), limits the lead content of cocoa powder or beans to $1 \mu \mathrm{g}$ of lead per gram product (FAO/WHO 1981). Analysis of a variety of chocolate products from various global locations, completed by a Swiss research group in 2002, found that the lead contents of these items ranged from $0.011 \mu \mathrm{g}$ to $0.769 \mu \mathrm{g}$ per gram, below the international standards (Mounicou et al. 2003).

\begin{tabular}{|c|c|c|c|}
\hline \multirow[t]{2}{*}{ Food } & $\begin{array}{c}\text { No. } \\
\text { samples }\end{array}$ & $\begin{array}{c}\text { Mean lead } \\
\text { concentration }\end{array}$ & $\begin{array}{l}\text { Standard } \\
\text { deviation }\end{array}$ \\
\hline & & \multicolumn{2}{|c|}{$\ldots \ldots \ldots \mu g / g \ldots \ldots \ldots$} \\
\hline $\begin{array}{l}\text { Dark chocolate } \\
\text { pieces }\end{array}$ & 8 & 0.0965 & 0.0892 \\
\hline Milk chocolate bar & 12 & 0.0418 & 0.0705 \\
\hline $\begin{array}{l}\text { Premium milk } \\
\text { chocolate bar }\end{array}$ & 12 & 0.0949 & 0.1160 \\
\hline $\begin{array}{l}\text { Candy-coated } \\
\text { chocolate }\end{array}$ & 8 & 0.0010 & 0.0020 \\
\hline
\end{tabular}

This, coupled with research suggesting that only $5 \%$ to $10 \%$ of lead contained in cocoa is bioavailable to the body (Mounicou et al. 2002), suggests that there is limited risk of lead toxicity to regular consumers of chocolate products.

Calcium supplements. Historically, calcium supplements have also been found to contain lead. Deposits of calcium that are mined for supplements may contain lead. Recent lab analysis of 21 different over-the-counter products completed in 2000 demonstrated that 11 had detectable lead levels, between 1 and $3 \mu \mathrm{g}$ per dose (Ross et al. 2000). In California, analyses of 136 products demonstrated that approximately $67 \%$ exceeded $1.5 \mu \mathrm{g}$ of lead per dose, the tolerable level set by Proposition 65 regulations (Scelfo and Flegal 2000). (Prop. 65 was enacted to protect and inform Californians about exposure from harmful chemicals.) Although intestinal absorption of lead is reduced in the presence of calcium, it is not completely inhibited. Considering that many Americans consume calcium supplements on a daily basis per recommendations from their physicians, the potential for lead contamination from these products should not be ignored. However, consumption of calcium supplements effectively reduces the risk of osteoporosis, and until further research is completed, it should be maintained that the benefits of supplement usage outweigh the risks.

\section{Ongoing surveillance needed}

Ongoing surveillance of lead levels in environmental and food sources is imperative to ensure that appropriate actions can be taken in a timely fashion.

Our review suggests that elevated levels of lead occur in paint, dust, soil, imported pottery and ceramic ware, ethnic remedies, and some imported candies. Furthermore, although the monitoring of lead levels in candy should continue, current data suggests that in the United States the risk of lead toxicity from these items is relatively low. If future analysis shows lead contamination of such food

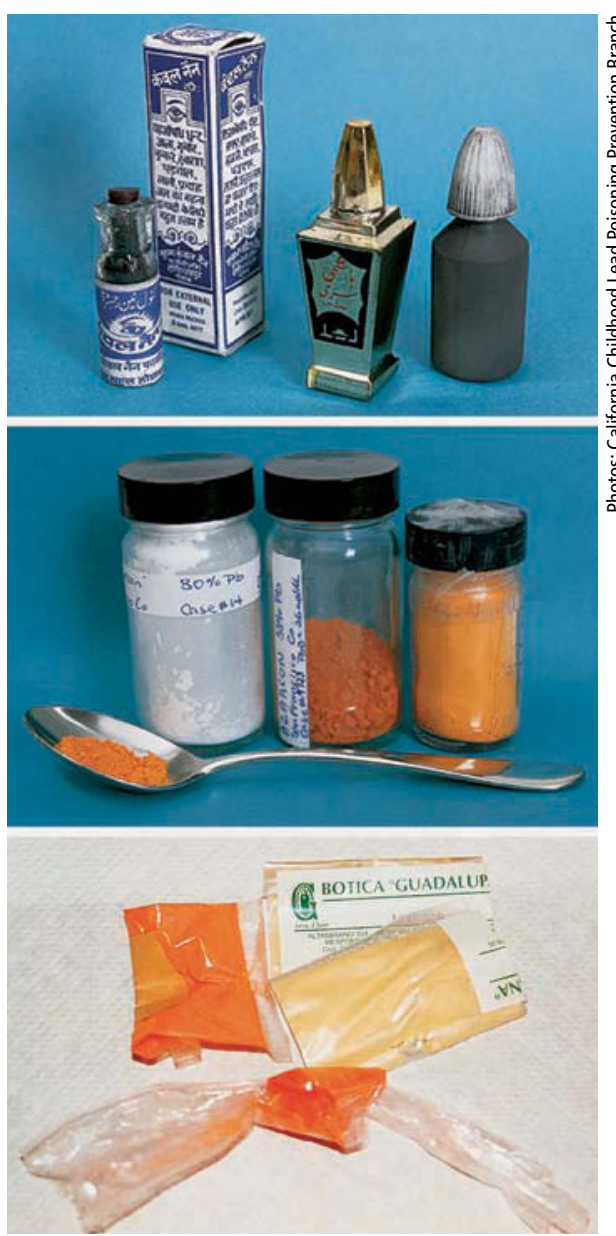

Large amounts of lead have been found in certain ethnic remedies. Top, surma or kohl is applied to children's eyes in some Asian communities. Center and bottom, azarcon and greta are used to treat intestinal and stomach ailments in some Latino communities.

products, methods should be developed to reduce their lead content.

Due to drastic reductions in lead in the ambient air and food, bloodlead levels in children and the general U.S. population are now lower than they were 1 or 2 decades ago (EPA 2004b); however, NHANES and CDC data suggests that between $2 \%$ and $3 \%$ of American children still exhibit elevated levels of blood lead (Meyer et al. 2003). At the present time, therapy for children with blood-lead levels between $10 \mu \mathrm{g} / \mathrm{dL}$ and $20 \mu \mathrm{g} / \mathrm{dL}$ is limited to education and efforts to remove sources of lead in the child's environment, and no action is taken for children with blood levels less than $10 \mu \mathrm{g} / \mathrm{dL}$.

Studies show that the education and counseling of parents and children is effective in reducing blood-lead levels, in concert with the careful removal of 


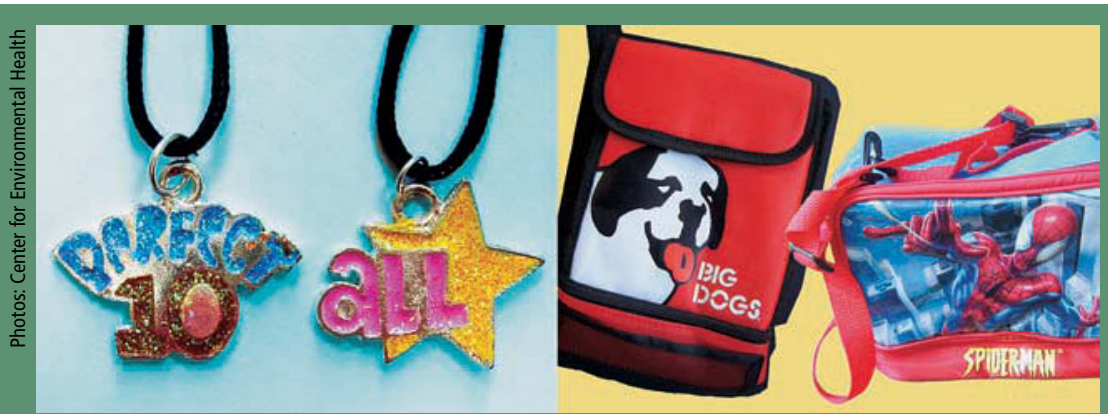

In recent years, lead has been detected in children's jewelry and soft vinyl (PVC) lunchboxes. In 2005, the Center for Environmental Health, a nonprofit based in Oakland, initiated lawsuits against retailers and manufacturers of these products, resulting in widespread reformulation to reduce lead content. In July 2006, the U.S. Food and Drug Administration warned lunchbox manufacturers to stop marketing vinyl lunchboxes containing any level of lead that may leach into children's food.

For more information, go to www.cehca.org.

hot spots such as peeling paint on window sills and porch banisters (Rooney et al. 1994). Most importantly, studies have demonstrated that cognitive function improved when moderate bloodlead levels in children were reduced (Kimbrough et al. 1994). Perhaps the parents of children with levels between $5 \mu \mathrm{g} / \mathrm{dL}$ and $10 \mu \mathrm{g} / \mathrm{dL}$ should also be included in these education programs to ensure that they are adequately educated on the risk factors associated with lead exposure. In the future, sustained efforts to reduce the lead exposure of American children will be necessary to achieve the Healthy People 2010 goal of eliminating all elevated blood-lead levels in children.

K. Heneman is Postdoctoral Researcher, and S. Zidenberg-Cherr is Cooperative Extension Specialist, Department of Nutrition, UC Davis.

\section{References}

Abadin H, Llados F. 1999. Toxicological profile for lead. Agency for Toxic Substances and Disease Registry, Centers for Disease Control and Prevention, Atlanta, GA. www.atsdr.cdc.gov/toxprofiles/tp13.html.

August K, Brooks L. 2004. State Health Department warns consumers not to eat chaca chaca, lead-contaminated candy from Mexico. California Department of Health Services, Sacramento, CA. www.applications.dhs. ca.gov/pressreleases/store/PressReleases/04-15.html.

Bernard SM, McGeehin MA. 2003. Prevalence of blood lead levels $>$ or $=5$ micro $\mathrm{g} / \mathrm{dL}$ among US children 1 to 5 years of age and socioeconomic and demographic factors associated with blood of lead levels 5 to $10 \mathrm{micro} g / \mathrm{dL}$. Third National Health and Nutrition Examination Survey, 1988-1994. Pediatrics $112(6 \mathrm{Pt}$ 1):1308-13.

Canfield RL, Henderson Jr CR, Cory-Slechta DA, et al. 2003. Intellectual impairment in children with blood lead concentrations below 10 microg per deciliter. N Engl J Med 348(16):1517-26.
[CDC] Centers for Disease Control and Prevention. 1991. Preventing lead poisoning in young children: A statement by the Centers for Disease Control. US Department of Health and Human Services, Atlanta, GA. www.cdc.gov/ NCEH/lead/Publications/books/plpyc/contents.htm.

CDC. 1993. Lead poisoning associated with use of traditional ethnic remedies — California, 1991-1992. MMWR 42(27):521-4.

CDC. 2003. Tested and confirmed elevated blood lead levels by state, year, and blood level group for children < 72 mos. Atlanta, GA. www.cdc.gov/NCEH/ lead/surv/database/State_Confirmed_byYear_2004_ for\%20website.xls.

CDC. 2005. Lead in candy: Questions and answers. Atlanta, GA. www.cdc.gov/nceh/lead/faq/candy.htm.

Davis T. 2005. Getting the lead out: The ongoing quest for safe drinking water in the nation's capital. US House of Representatives, Committee on Government Reform. http://reform.house.gov/GovReform/Hearings/ EventSingle.aspx?EventID=23039.

[DHHS]. US Department of Health and Human Services. 2000. Healthy People 2010: Understanding and Improving Health. www.healthypeople.gov/Document/ tableofcontents.htm\#under.

[DHS] California Department of Health Services 2003a. Children at Risk. Childhood Lead Poisoning Prevention Branch, Sacramento, CA. www.dhs.ca.gov/ childlead/html/clppb.html.

DHS. 2003b. Lead in Tableware - Resources. Childhood Lead Poisoning Prevention Branch, Sacramento,

CA. www.dhs.ca.gov/childlead/tableware/twhome.html.

DHS. 2005. Lead in Candy - 2005 Laboratory Results. Sacramento, CA. www.dhs.ca.gov/fdb/PDF/ 05\%20candy\%20results\%20for \%20web\%20final.pdf.

[EPA] US Environmental Protection Agency. 2004a. America's children and the environment. Washington, DC. www.epa.gov/envirohealth/children/index.htm.

EPA. 2004b. Measure B1: Lead in the blood of children. Washington, DC. www.epa.gov/economics/ children/body_burdens/b1.htm.

EPA. 2005. Lead in drinking water. Washington, DC. www.epa.gov/safewater/lcrmr/fs_consumer.html.

[FAOMHO] United Nations' Food and Agriculture Organization and World Health Organization. 1981. Codex Alimentarius. Codex Standard for Chocolate 87. www.codexalimentarius.net/web/standard_list.jsp.

[FDA] US Food and Drug Administration. 2004a. FDA statement on lead contamination in certain candy products imported from Mexico. Washington, DC. www. fda.gov/bbs/topics/news/2004/new01048.html.

FDA. 2004b. Total diet study statistics on element results. Washington, DC. www.cfsan.fda.gov/ acrobat/ tds1byel.pdf. p 58-68.
Fuortes L, Bauer E. 2000. Lead contamination of imported candy wrappers. Vet Hum Toxicol 42(1):41-2.

[GAO] US General Accounting Office. 1999. Lead poisoning: Federal health care programs are not effectively reaching at-risk children. www.gao.gov/archive/1999/ he99018.pdf.

Kimbrough RD, LeVois M, Webb DR. 1994. Management of children with slightly elevated blood lead levels. Pediatrics 93(2):188-91.

Koplan JP. 2002. Managing elevated blood lead levels among children. Centers for Disease Control and Prevention, Atlanta, GA. www.cdc.gov/nceh/lead/CaseManagement/caseManage_main.htm.

Landrigan PJ, Schechter CB, Lipton JM, et al. 2002 Environmental pollutants and disease in American children: Estimates of morbidity, mortality, and costs for lead poisoning, asthma, cancer, and developmental disabilities. Environ Health Perspect 110(7):721-8.

Lanphear BP, Dietrich K, Auinger P, Cox C. 2000. Cognitive deficits associated with blood lead concentration $<10$ microg/dL in US children and adolescents. Public Health Rep 115(6):521-9.

Lynch RA, Boatright DT, Moss SK. 2000. Leadcontaminated imported tamarind candy and children's blood lead levels. Public Health Rep 115(6):537-43.

Matte TD, Proops D, Palazuelos E, et al. 1994. Acute high-dose lead exposure from beverage contaminated by traditional Mexican pottery. Lancet 344(8929):1064-5.

Meyer PA, Pivetz T, Dignam TA, et al. 2003. Surveillance for elevated blood lead levels among children - United States, 1997-2001. MMWR Surv Summ 52(10):1-21.

Mielke HW, Reagan PL. 1998. Soil is an important pathway of human lead exposure. Environ Health Perspect 106 Suppl 1:217-29.

Millett J. 2005. EPA to strengthen protection from lead in drinking water. US Environmental Protection Agency, Washington, DC. Press release.http://yosemite.epa.gov/ opa/admpress

Mounicou S, Szpunar J, Andrey D, et al. 2002. Development of a sequential enzymolysis approach for the evaluation of the bioaccessibility of $\mathrm{Cd}$ and $\mathrm{Pb}$ from cocoa. Analyst 127(12):1638-41.

Mounicou S, Szpunar J, Andrey D, et al. 2003. Concentrations and bioavailability of cadmium and lead in cocoa powder and related products. Food Addit Contam 20(4):343-52.

Needleman HL, Schell A, Bellinger D, et al. 1990. The long-term effects of exposure to low doses of lead in childhood. An 11-year follow-up report. N Engl J Med 322(2):83-8.

Nordin JD, Rolnick SJ, Griffin, JM. 1994. Prevalence of excess lead absorption and associated risk factors in children enrolled in a midwestern health maintenance organization. Pediatrics 93(2):172-7.

Nriagu JO, Pacyna JM. 1988. Quantitative assessment of worldwide contamination of air, water and soils by trace metals. Nature 333:134-9.

Rooney BL, Hayes EB, Allen BK, Strutt PJ. 1994. Development of a screening tool for prediction of children at risk for lead exposure in a midwestern clinical setting. Pediatrics 93(2):183-7.

Ross EA, Szabo NJ, Tebbett IR. 2000. Lead content of calcium supplements. JAMA 284(11):1425-9.

Saper RB, Kales SN, Paquin J, et al. 2004. Heavy metal content of ayurvedic herbal medicine products. JAMA 292(23):2868-73.

Scelfo GM, Flegal AR. 2000. Lead in calcium supplements. Environ Health Perspect 108(4):309-19.

Sprinkle RV. 1995. Leaded eye cosmetics: A cultural cause of elevated lead levels in children. J Fam Pract 40(4):358-62. 